\title{
Cycles and trends in the dynamics of a leaning tower. Eight years of geometric monitoring with surveying techniques
}

\author{
Ciclos y tendencias de la dinámica de una torre inclinada: ocho años de control geométrico \\ mediante técnicas topográficas
}

Pablo Pérez Vidiella (Main Author)

Laboratorio de Documentación Geométrica del Patrimonio. Universidad del País Vasco/Euskal Herriko Unibertsitatea UPV/EHU

Idgp@ehu.eus

\section{Álvaro Rodríguez Miranda}

Laboratorio de Documentación Geométrica del Patrimonio - Grupo de Investigación en Patrimonio Construido Universidad del País Vasco/Euskal Herriko Unibertsitatea UPV/EHU

alvaro_rodriguez@ehu.eus

José M. Valle Melón (Corresponding Author)

Laboratorio de Documentación Geométrica del Patrimonio - Grupo de Investigación en Patrimonio Construido Universidad del País Vasco/Euskal Herriko Unibertsitatea UPV/EHU

c/ Justo Vélez de Elorriaga, 1 (Centro de Investigación Micaela Portilla)

01006, Vitoria-Gasteiz, Spain

jm.valle@ehu.eus

Ane Lopetegi Galarraga

Escuela Universitaria de Ingeniería de Vitoria-Gasteiz

Universidad del País Vasco/Euskal Herriko Unibertsitatea UPV/EHU

ane.lopetegui@ehu.eus

Manuscript Code: 791

Date of Acceptance/Reception: 04.04.2017/26.07.2016

DOI: $10.7764 /$ RDLC.16.1.158

\section{Abstract}

This paper presents the methodology and results of the geometric monitoring of a leaning tower (Santa María la Blanca church in Agoncillo, La Rioja, Spain) with surveying techniques. Throughout the period 2007-2014, two types of variations in the geometry of the building have been tracked: those due to a seasonal cycle (winter-summer) and those caused by the progressive increase in the leaning of the tower. The text describes the distribution of the control points, the fieldwork, the computation strategy and the way to ensure that the results are significant. By way of conclusion, this work discusses the applicability of these techniques to the monitoring of historic buildings.

Key words: Geometric monitoring, historic building, surveying, cyclic movements, accumulative movements.

\section{Resumen}

En el presente artículo se exponen la metodología seguida y los resultados obtenidos en el control geométrico de una torre inclinada (iglesia de Santa María la Blanca en Agoncillo, La Rioja, España) mediante técnicas topográficas clásicas durante el periodo 2007-2014. En este tiempo, se han podido detectar variaciones en la geometría del edificio tanto debidas a un ciclo estacional (invierno-verano) como al incremento acumulativo en la inclinación de la torre. El texto describe la distribución de los puntos de control, el trabajo de campo, la estrategia de cálculo y la forma de asegurar que los resultados son significativos. Para concluir, se discute la aplicabilidad de estas técnicas a los estudios estructurales de edificios históricos.

Palabras clave: Control geométrico, edificio histórico, topografía, movimientos cíclicos, movimientos acumulativos.

Introduction

Studies in the stability of historic buildings are based on the combination of four activities (Roca, 2009): (1) bibliographical review of its history and the development of the construction, (2) inspection, (3) monitoring of the evolution of its pathologies and (4) structural analyses. Within this framework, the applicability of the techniques for the geometric documentation has traditionally been twofold: recording the current state and tracking the changes over time. On the one hand, assessing the current condition of the building allows us to produce three-dimensional models that may be used as the basis for structural analyses. Moreover, the values required for the calibration of the models, 
on which the aforementioned analyses are based, can be gathered from sustained measures along time of the -relative or absolute- movements and the deformation undergone by some specific areas or complete surfaces.

Put in a different way, the geometric monitoring of pathologies (cracks, out-of-plumb walls, etc.) over time can not only elucidate their causes but also determine the time when it will be necessary to take steps to prevent the collapse of the structure and avoid personal risks (Díaz, Cornadó, Santamaría, Rosell \& Navarro, 2015).

The following sections present a case study of monitoring of a leaning tower carried out by means of the so-called "traditional" surveying techniques (that is to say: theodolite and electronic distance measurements). The study consisted of two phases, one from 2007 to 2009 and the other in 2014 . The analysis of this case turns out a number of common features, problems and good-practice criteria that can be applied to similar projects, regardless of the monitoring methodologies selected for each project.

\section{Description of the problem}

The church of Santa María la Blanca of Agoncillo (La Rioja, Spain) was built in ashlar masonry during the 17th and 18th centuries. It is a three nave construction with chapels. The ground surface of the main edifice is around 12 by 30 meters by 20 meters high. Although it holds some remarkable pieces of furniture and sculpture, out of the canon of art historians, the building is mainly known for the noticeable leaning of the annexed tower in relation to the church (approximately two sexagesimal degrees). The tower reaches 35 meters above ground level. It has a square floor plan of 6 by 6 meters at the base and an octagonal belfry crowned with a lantern dome on top (Figure 1).

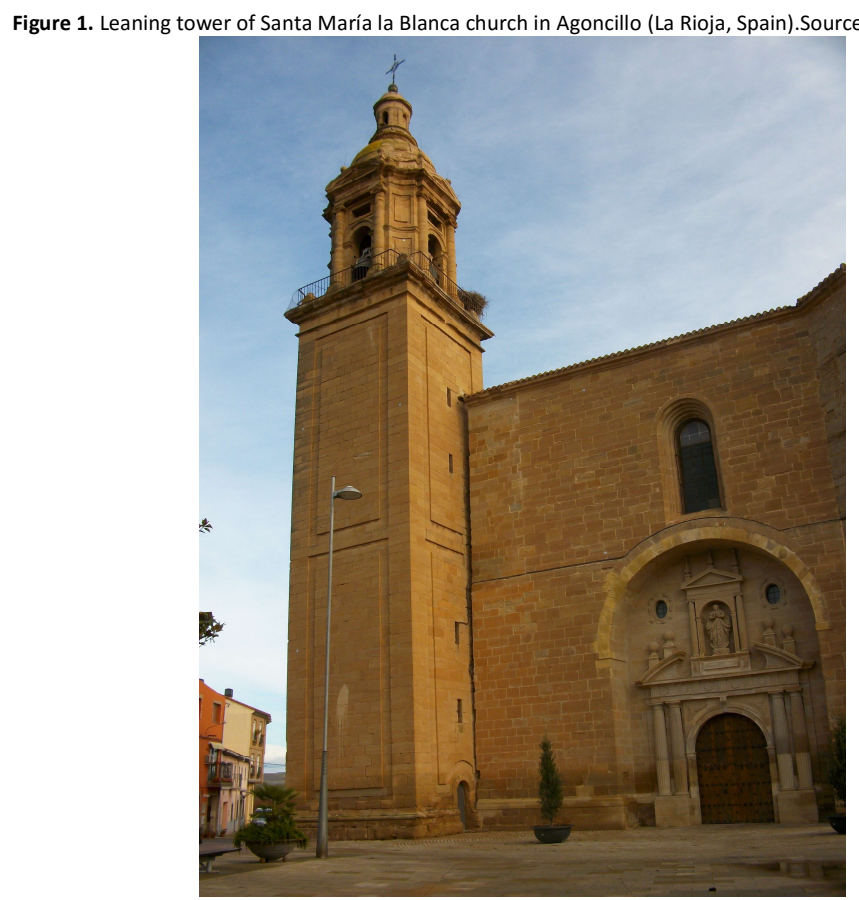

The appeal of leaning towers is noteworthy. Indeed, several successful experiences can be recalled in which the leaning itself has made a building an icon of the local or national heritage and a first class tourist attraction. Undeniably, towers are often the most impressive part of churches and, hence, of many of the towns and cities where they are located. As a result, the decay of a tower causes concern with safety as well as the expectation -somewhat malicious- of contemplating a building on the verge of collapsing with a loud din.

In the specific case of the church of Agoncillo, the starting point was the lack of reliable information on the behaviour of the building. Before 2007, there were only highly subjective impressions of the inhabitants, who did not even agree when it came to deciding whether or not the gap between the tower and the church had increased over the years. Against this backdrop, it was decided to carry out a monitoring project for the period 2007-2009 that involved a broad area of the building in order to assess the magnitude of the problem. Thus, the study considered the tower and both façades of the church (north and west), to which the tower is annexed. Forty control points were set at different heights 
all over this area of the building plus nine additional targets on the surrounding constructions (Valle Melón, Rodríguez Miranda, \& Pérez Vidiella, 2008).

The measurements with total station were done from the square in front of the main façade (to the west) and the vacant lot (to the north). Figure 2 shows these two spaces as well as the location of the control points on the building. For the majority of these locations, two markers were placed very close to each other, both were measured and computed independently in order to detect observation mistakes and remove them from the calculations, in addition, by resorting to a redundant signalling system, any possible detachment or movement of the points (not linked to the movement of the walls) can be more easily spotted. The computation of the coordinates of these targets was done by means of least squares adjustment of the angular intersections and reached an accuracy of $2 \mathrm{~mm}$ (established by the semi-major axis of the $95 \%$ confidence ellipses provided by the adjustment at each point).

Figure 2. Open spaces around the tower from which the survey observations were carried out. The numbers on the pictures indicate the location and codes of the control points. Total station was arbitrarily set up by resection in eight positions at each epoch, the coordinates of the stationing points were auxiliary and valid only for that specific epoch since the points were not marked on the ground and, therefore, could not be reoccupied. Source: self-elaboration.
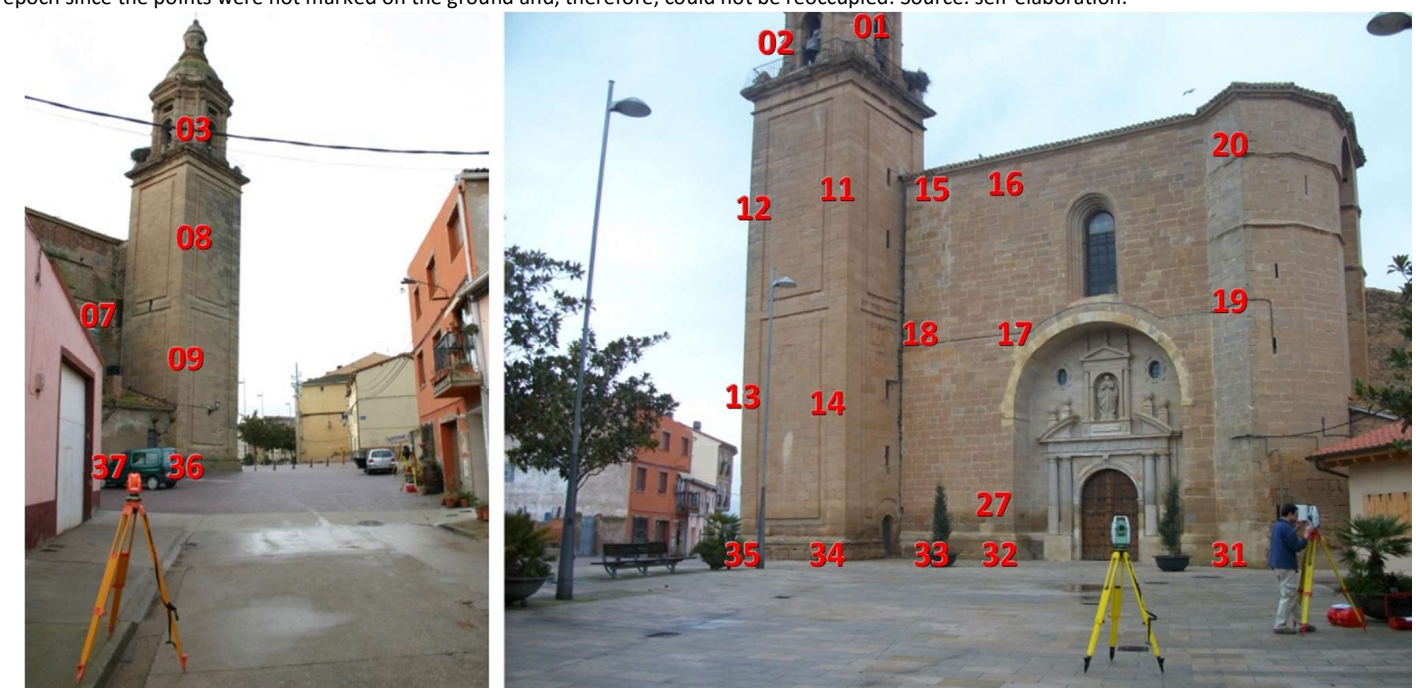

Individual movements between epochs were determined two-dimensionally (in the XY plane) since this approach greatly simplifies the computation. Nevertheless, the three-dimensional behaviour of the structure can be still inferred from the displacements of the group of targets placed at different heights in the same vertical line (such as locations 1 , 11, 14 and 34). For instance, an increase of the leaning will create a coherent set of $2 \mathrm{D}$ vectors pointing at the same direction, the magnitude of each rising gradually the higher they are. In addition, should this increase happen, a similar pattern is to be expected in groups $(2,12,13,35)$ and $(3,8,9,36)$.

The definition of the reference system used for the calculations might require further explanation. As the observation scheme did not include permanent benchmarks for setting up the total station (e.g. pillars) which could serve as reference points, the adjustment computations were based on minimum constraints. Only angles were used in order to keep the measurements as controlled as possible, for a two-dimensional network, this means that two points need to be considered fixed. These reference points were selected at the base of the building (locations 31 and 35 in figure 2) for three reasons: firstly because they were clearly visible from everywhere in the square, therefore, their determination by means of angular intersection reaches the maximum accuracy of all points, secondly, both targets could be visually inspected at the beginning of each epoch, thus verifying that they remain unaltered and, finally, due to the fact that this decision cancelled out the horizontal displacements at ground level and thereby facilitated the detection of the aforementioned patterns of $2 \mathrm{D}$ movements correlated with the high of the targets.

All in all, 10 epochs of measurements were carried out every three months from July 2007 to October 2009. comparison between data from the same season (winter, spring, summer or autumn) in different years did not turn out deep discrepancies, that is to say, bigger than the uncertainty of the coordinates themselves. Nevertheless, the contrast between the coordinates calculated in winter and summer did show significant changes, according to a pattern that repeated year after year and that could be modelled, in a first approximation, as a cyclic oscillation that modifies the leaning of the tower with an amplitude of nineteen sexagesimal seconds (Valle-Melón, Rodríguez-Miranda, \& PérezVidiella, 2011). 
Five years after the end of this phase of the monitoring, it was decided to carry out two additional epochs corresponding to winter and summer of the year 2014. The specific objectives of these new campaigns were:

1. Verifying the existence and the magnitude of the cyclic oscillation due to the seasonal change winter/summer that was detected for the period 2007-2009.

2. Checking whether there had been accumulative movements and, more specifically, those that cause the permanent increase in the leaning of the tower.

\section{State of the Art}

The use of angle and distance measurements for the geometric monitoring of many major works of engineering, including not only dams and bridges but also historic buildings, throughout their service life has been a standard procedure over the last decades (US Army Corps of Engineers, 2002, 2007). These methodologies are based on the control of a series of selected points, the coordinates of which are computed in different epochs. Then, the differences are modelled with the aim of defining the behaviour of the structure (Welsch \& Heunecke, 2001).

In this respect, it is worth reviewing, however briefly, the current scenario as far as equipment and measuring techniques are concerned. For instance, and without leaving the techniques based on monitoring selected points by means of series of angle and distance measurements, manual schemes of observation (Papastamos, Stiros, Saltogianni, \& Kontogianni, 2015) are nowadays complemented -and gradually replaced-by robotic systems that allow us to set up the total station at defined places and that can take measurements repeatedly in an autonomous way. Moreover, they update the computation as often as required, which is very useful for the monitoring of works in progress since the system can warn in real-time if the displacements exceed the pre-established safety limits (Pachón, Rodríguez-Mayorga, Cobo, \& Yanes, 2014). In general, the possibilities of registering data on the geometry of the buildings also include:

- In the first place, mass capture devices, such as laser scanners and techniques of automated photogrammetry, whose development has replaced the analysis of individual points with the study of the behaviour of complete surfaces. Different works (among others Bayarri Cayón \& Castillo López, 2014; Camp, Carreaud \& Lançon, 2013; Lluis i Ginovart, Costa, Toldrà \& Coll, 2014; Pesci, Casula \& Boschi, 2011; Teza \& Pesci, 2013) compare the actual measured surfaces with the theoretical ones: vertical planes, fitting to cylindrical or spherical shapes, etc. It must be noted in this respect that the current geometry of historic buildings tends to be different from the original project due to their prolonged existence and historical vicissitudes (Cámara \& Latorre, 2003), although this difference does not necessarily entail the instability of the structures. Another application of mass data is the generation of geometric models of the current state of the building in a faster and detailed way (in relation to the classical techniques) in order to represent the existent pathologies in more detail (Cámara, 2010) and contribute to the structural analysis by means of different techniques such as the "thrust line method" (Rodríguez-Mayorga, Yanes-Bustamante, \& SáezPérez, 2015; Schueremans, 2008) or the "finite elements method" (FEM) analysis (Camarda, Guarnieri, Milan, \& Vettore, 2010; Fregonese et al., 2013; Pieraccini et al., 2014, etc.).

- Secondly, there are other devices that provide information on the spatial and dimensional behaviour of the structures, such as extensometers, clinometers, etc. (Albert, Fernández, Fuente, Martínez, \& Yuste, 2009; Lorenzoni, Casarin, Caldon, Islami, \& Modena, 2016; Marcos Rodríguez \& San Mateos Carretón, 2006). It has to be borne in mind that the geometry is only a part of the monitoring. Both the tracking and the structural modelling need to take into account more factors, such as the material composition of the building and the state of such materials, environmental and climatic variables, dynamic causes (like the effect of the chiming of the bells in the case of belfries like the one studied in this work) and so on. All these values can be recorded with the help of a broad variety of sensors (ultrasounds, ground-penetrating radar, thermography, etc.) and laboratory tests that, considered together, give us insight into the health of the building and its behaviour.

It is pertinent to mention that the very phenomenon can manifest itself in the building through different pathologies and can be detected in different ways. For instance, the settling of the ground can be tracked by means of a levelling network placed at the base of the building but also by watching the evolution of the cracks or the leaning of the walls. In general, it is beneficial to integrate several techniques, since each provides a complementary point of view. This is useful in order to confirm the results provided by the rest of techniques and so as to corroborate the different hypotheses about the reasons for the origin of the instability and their consequences. 
In this context, the deeper the previous knowledge of the possible causes is, the easier it will be to predict their effects and the magnitude of the displacements. Thus, a better selection will be possible of the devices and monitoring techniques as well as the critical places on which observations have to be focused. Nevertheless, the selection of techniques and devices will also be determined by other factors like the characteristics and uses of the building, its surroundings, the time span of measures and the available resources.

Methodology

The monitoring with surveying techniques is based on the comparison of coordinates. The interpretation of differences either as simple noise or due to cyclic, accumulative, random or unexplained movements depends on the rate magnitude/error, on how much time separates both epochs and whether patterns can be detected or not. Another key factor is to understand that results are always presented with a certain degree of fuzziness. For instance, concluding that the coordinates of a point measured in 2007, 2008 and 2009 did not change with the accuracy of the measures does not imply that there was not any movement whatsoever, but that, if some movement took place in that period of time, its magnitude would be lower than the value of the accuracy just mentioned. Therefore, it is essential to gauge the accuracy of the results before drawing conclusions (Armesto, Arias, Roca \& Lorenzo, 2008), while reducing the uncertainties reinforces the significance of such conclusions.

In statistics, the law for the propagation of uncertainties stipulates that, if we know the magnitude of the error in the coordinates computed for the same point in two epochs 1 and 2 -that are represented as e1 and e2-, the error due to the determination of the displacement -ed- that has taken place between the epochs (in other words, the error of the subtraction of the coordinates) is:

$e_{d}=\sqrt{e_{1}^{2}+e_{2}^{2}}$

Now, we are interested in calculating the average speed of an accumulative displacement, which is to be detected in epochs measured in the same month but in different years. To do this, we divide the total displacement between the epochs (the difference of the coordinates) by the time elapsed. The same applies to the error associated to that speed $-e_{s}-$.

$e_{S}=\frac{\sqrt{e_{1}^{2}+e_{2}^{2}}}{t i m e}$

This value constitutes the limit of discrimination under which the accuracy of the measurements and the computations do not allow us to identify displacements that happened during the time elapsed between both epochs. Therefore, when attempting to detect accumulative movements it is necessary to let enough time pass, so that the magnitude of the displacements is larger than the limit of discrimination of the methodology used for the monitoring.

The results in table 1 were calculated on the assumption that the error of the coordinates for each epoch of observation in the tower of Agoncillo (e1 and e2) was $2 \mathrm{~mm}$. The table shows the values of the error of the average speed according to the number of years that passed between the epochs. It is necessary, nevertheless, that the difference of the coordinates is meaningful and that we consider that this difference was caused by a movement of this kind -which usually requires the detection of displacements at several points and that they are consistent with this behaviour.

Table 1. Error in the determination of the average speed of a supposed accumulative movement,
as a function of years elapsed (based on the assumption that $\mathrm{e}=\mathrm{e} 2=2 \mathrm{~mm}$ ). Source: self-
elaboration.
\begin{tabular}{cc} 
Years elapsed & $\begin{array}{c}\text { Error of the average speed - } \\
e_{s^{-}}(\mathrm{mm} / \text { year) }\end{array}$ \\
\hline 1 & 2.8 \\
2 & 1.4 \\
3 & 0.9 \\
4 & 0.7 \\
5 & 0.6 \\
\hline
\end{tabular}




\begin{tabular}{cc}
\hline 6 & 0.5 \\
7 & 0.4 \\
10 & 0.3 \\
15 & 0.2 \\
\hline
\end{tabular}

Given the values in the table, the fact that, for the first phase of the monitoring (the period 2007-2009), accumulative movements were not detected indicates that, if such movements existed, their average speed must have been lower than $1.4 \mathrm{~mm} /$ year. However, with the new epochs measured in 2014, the time span enlarged considerably, which allowed us to refine the hypotheses and conclusions of the 2009 phase.

When it came to planning the campaigns in 2014 the situation was quite different from 2007, given that the experience gained during the previous phase allowed us to know in which points of the control network the changes could be seen more clearly and also because the procedures for data recording and processing had been fine-tuned in order to ensure the accuracy needed to obtain conclusive results.

One of the main challenges for monitoring studies that go on for periods of several years is the maintenance of the markers. The usual issues of degradation due to oxidation, deformation, detachment or erasure of the signs that exist in any restricted access structure (a fenced off work area, a dam, etc.) go hand in hand, in the buildings accessible to the public, with the possibility that the markers disappear because of vandalism or restoration works.

Of special relevance for our study was the restoration of the main façade that we found in 2014. In that work, cracks were covered and degraded stones replaced, especially at the base of the building and near the entrance (Figure 3 ). Four markers were removed as a result of this intervention, including many of the ones placed at the bottom of the building (in particular, locations 31, 32 and 33 in figure 2) and, even worse, one that had been used to define the reference system relative to which the measurement of the leaning was calculated. Furthermore, several surrounding buildings had also been restored or rebuilt during the time span of our study with the resulting loss of some external markers. Consequently, previous to the observation of new measurements it was necessary to place new control points in the empty areas.

Figure 3. Photographs taken before (left) and after (right) the restoration of the façade, done at some moment between 2009 and 2014 . Source: self-elaboration.
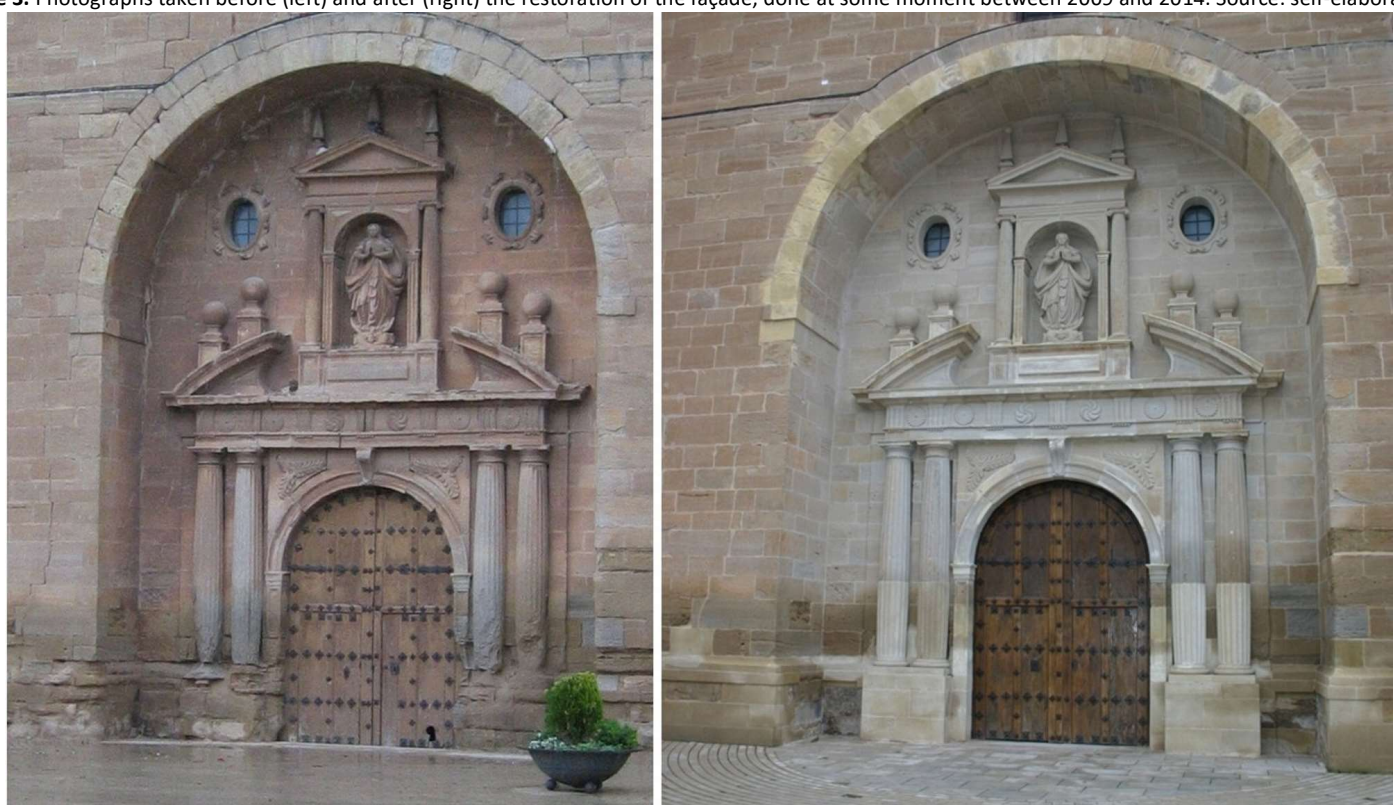

In order to be able to compare the coordinates obtained in different epochs it is necessary that all of them are computed by using the same reference system. Considering that in 2014, due to the loss of control points, it was no longer possible to use the reference system of previous computations, it was necessary to define a new one based on another pair of points that had been present during the whole observation period (from 2007 to 2014), in particular, points at locations 
35 and 27 in figure 2 were selected. Then, all the epochs for the period 2007-2009 were recalculated in relation to this new system, in such a way that their values could be cross-checked with the measurements made in 2014.

In a nutshell, it can be said that the campaigns of 2014 confirmed the seasonal cycle and the detection of an accumulative movement.

In order to describe the results, let us have a look at locations 1, 2 and 3 (see figure 2), the ones situated at the top of the tower since they show the differences more clearly. As there are two control points for each location, we have six samples of the difference among epochs (indicated as "C01", "D01", "C02", "D02", "C03" and "D03"). Figure 4 displays the charts corresponding to all six points. For each point, four positions with their uncertainties are drawn: average for winter 2007-2009 (dark red), average for summer 2007-2009 (dark blue), winter 2014 (light red) and summer 2014 (light blue). In the charts, position is represented by the centre of the ellipse and uncertainty by the ellipse itself.

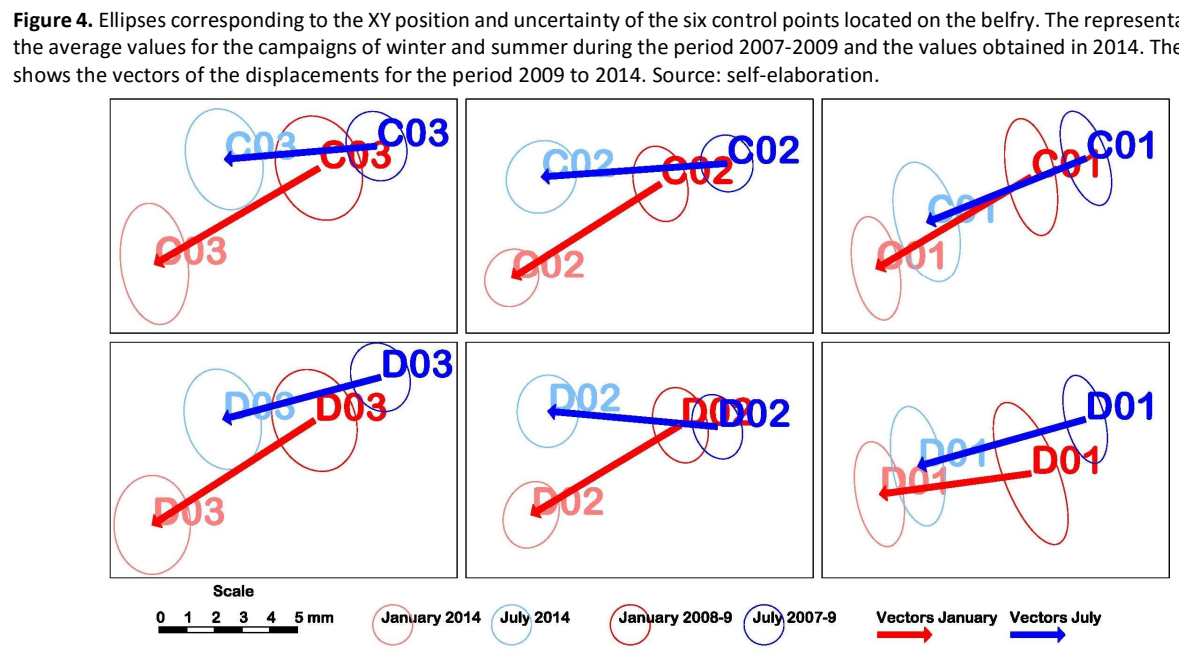

To begin with, figure 4 shows that, except for "D01", the error ellipses corresponding to the coordinates of the control points computed for the campaigns of January and July 2014 (light ellipses) are clearly separated, thus confirming the existence of the seasonal cycle already detected in the campaigns of the period 2007-2009 (dark ellipses).

As far as the accumulative movements are concerned, figure 4 shows the vectors corresponding to the displacements between the positions of January and July after the five elapsed years. The direction of these vectors is consistent with an increase in the leaning angle with respect to the church, the average length being $6 \mathrm{~mm}$. If it is assumed that this displacement is the result of a movement with constant speed in progress throughout all the time, the speed of the aforesaid movement can be estimated in around $1.2 \mathrm{~mm} / \mathrm{year}$.

According to the values in table 1, over a five-year period and considering an uncertainty of 2 mm for the coordinated of each epoch, the error with which the speed can be determined is $0.6 \mathrm{~mm} / \mathrm{year}$, which means that the resulting value $(1.2 \mathrm{~mm} /$ year) is significant. What is more, this estimated speed is in line with the result obtained after the analysis of the campaigns 2007-2009, when the conclusion was reached that, if accumulative movements exist, their speed should be under $1.4 \mathrm{~mm} /$ year.

As told before, the interpretation of both the cycle and the accumulative movement as due to the increase in the leaning of the tower is also supported by the rest of the control points placed at different heights on the tower ( 21 points in total), which show vectors along the same direction but with lengths that are progressively smaller as the markers are closer to the ground. As the speed $1.2 \mathrm{~mm}$ /year was measured for the control points on the belfry (located around 25 meters above the ground), this variation can be also expressed as an angular increase in the leaning of the tower in the order of 10" (sexagesimal seconds) a year.

Discussion

The interpretation of the movement between 2007 and 2014 as an increase in the leaning of the tower with a constant speed should be considered as a working hypothesis. It goes without saying that accepting that the movements have 
remained constant during the period between campaigns and, furthermore, that they will keep constant in the following years is arguable (Pellegrinelli, Furini, \& Russo, 2014). Nevertheless, taking into account the available data, this is a useful way of explaining, at least broadly, the trend and allows for the prediction of the evolution for the following years. This estimation, moreover, can be checked and revised at any time by carrying out another campaign of observation of the control points.

In this kind of work, the markers need to be maintained in operating conditions for a number of years. It is also necessary to avoid negative effects to the aesthetics of the monument (although, this might be a subjective matter) and to minimize the disturbances to the normal use of the building by its inhabitants or visitors. In this respect, the inclusion of the geometric monitoring into the touristic value of the building requires that the monitoring is visible, for instance, by means of some type of informative plates that might even be part of the control points.

Thinking of long periods of observation also implies keeping the record of the observations. In other words, it is essential to save up the original data so that they can be recomputed if need be. The team will also need to preserve the technology and the equipment in order to be able to compare the different epochs of the project.

It is crucial to consider the socialization of the scientific knowledge, reassure the inhabitants and encourage them to play an active role in the care and dissemination of the monument. For these reasons, the project also included a public presentation of the results in the town in order to address questions, satisfy the curiosity of the inhabitants and have a new opportunity to chat with them about the issues and advances of the project.

\section{Conclusions}

The epochs conducted in the church of Agoncillo from 2007 to 2014 indicate the existence and gauge the magnitude of two different kinds of movements that affect the leaning of the tower: (1) an oscillation due to a seasonal cycle and (2) an accumulative increase.

These results are relevant for the maintenance of the building since the actions to do can be planned on the basis of objective data. Moreover, the knowledge on the dynamics of the construction can also be used for tourism promotion. Since the markers used as control points are still serviceable and the methodologies for the observation and the processing of the data have demonstrated their adequacy, it would be possible to extend the monitoring by means of new campaigns if deemed necessary.

Acknowledgements

The authors would like to express their gratitude to the Regional Government of La Rioja for the funding and to the inhabitants of Agoncillo for their hospitality and interest in the project.

References

Albert, V., Fernández, R., Fuente, J. V., Martínez, R., \& Yuste, J. (2009). Control estructural mediante monitorización remota: casos de aplicación. In Tecnología de la Rehabilitación y Gestión del Patrimonio Construido (REHABEND 2009) (pp. 63-83). Bilbao, Spain.

Armesto, J., Arias, P., Roca, J., \& Lorenzo, H. (2008). Monitoring and Assessing Structural Damage in Historic Buildings. The Photogrammetric Record, 23(121), 36-50. https://doi.org/10.1111/j.1477-9730.2008.00466.x

Bayarri Cayón, V., \& Castillo López, E. (2014). Los nuevos algoritmos de procesado y tendencias en geometría computacional para la explotación y valoración de datos en 3D. In REHABEND 2014. Congreso Latinoamericano. Patología de la Construcción, Tecnología de la Rehabilitación y Gestión del Patrimonio (pp. 571-579). Santander, Spain.

Cámara, L. (2010). Estratigrafía, evolución estructural y restauración. El caso de la iglesia de Santa Eulalia en Marquínez (Álava). Arqueología de La Arquitectura, (7), 225-260. https://doi.org/10.3989/arqarqt.2010.10006

Cámara, L., \& Latorre, P. (2003). El Modelo Analítico Tridimensional obtenido por fotogrametría. Descomposición, manipulación y aplicaciones en el campo de la restauración arquitectónica. Arqueología de La Arquitectura, (2), 87. https://doi.org/10.3989/arq.arqt.2003.29

Camp, G., Carreaud, P., \& Lançon, H. (2013). LARGE STRUCTURES: WHICH SOLUTIONS FOR HEALTH MONITORING? ISPRS - International Archives of the Photogrammetry, Remote Sensing and Spatial Information Sciences, XL-5/W2, 137-141. https://doi.org/10.5194/isprsarchives-XL-5-W2$137-2013$ 
Díaz, C., Cornadó, C., Santamaría, P., Rosell, J. R., \& Navarro, A. (2015). Actuación preventiva de diagnóstico y control de movimientos en los edificios afectados por subsidencia en el barrio de la Estación de Sallent (Barcelona). Informes de La Construcción, 67(538), 1-11. https://doi.org/10.3989/ic.13.168

Fregonese, L., Barbieri, G., Biolzi, L., Bocciarelli, M., Frigeri, A., \& Taffurelli, L. (2013). Surveying and Monitoring for Vulnerability Assessment of an Ancient Building. Sensors, 13(8), 9747-9773. https://doi.org/10.3390/s130809747

Guarnieri, A., Milan, N., \& Vettore, A. (2013). Monitoring Of Complex Structure For Structural Control Using Terrestrial Laser Scanning (Tls) And Photogrammetry. International Journal of Architectural Heritage, 7(1), 54-67. https://doi.org/10.1080/15583058.2011.606595

Lluis i Ginovart, J., Costa-Jover, A., Coll-Plà, S., \& Puche-Fontanilles, J. M. (2016). Techniques of massive data capture: A comparative approach for the assessment of complex spaces in architectural heritage. Revista de La Construcción, 15(1), 42-50. https://doi.org/10.4067/S0718915X2016000100004

Lorenzoni, F., Casarin, F., Caldon, M., Islami, K., \& Modena, C. (2016). Uncertainty quantification in structural health monitoring: Applications on cultural heritage buildings. Mechanical Systems and Signal Processing, 66-67, 268-281. https://doi.org/10.1016/j.ymssp.2015.04.032

Marcos Rodríguez, I., \& San Mateos Carretón, R. (2006). Monitorización de estructuras del patrimonio construido. In $1^{a}$ Jornada nacional sobre metodologías no destructivas aplicadas a la rehabilitación del patrimonio construido (REHABEND 2006) (pp. 120-139). Santander, Spain.

Pachón, P., Rodríguez-Mayorga, E., Cobo, A., \& Yanes, E. (2014). Control de la intervención estructural sobre el área del Teatro Romano de Cádiz. Informes de La Construcción, 66(Extra-1), 1-8. https://doi.org/10.3989/ic.13.086

Papastamos, G., Stiros, S., Saltogianni, V., \& Kontogianni, V. (2015). 3-D strong tilting observed in tall, isolated brick chimneys during the excavation of the Athens Metro. Applied Geomatics, 7(2), 115-121. https://doi.org/10.1007/s12518-014-0138-8

Pellegrinelli, A., Furini, A., \& Russo, P. (2014). Earthquakes and ancient leaning towers: Geodetic monitoring of the bell tower of San Benedetto Church in Ferrara (Italy). Journal of Cultural Heritage, 15(6), 687-691. https://doi.org/10.1016/j.culher.2013.12.005

Pesci, A., Casula, G., \& Boschi, E. (2011). Laser scanning the Garisenda and Asinelli towers in Bologna (Italy): Detailed deformation patterns of two ancient leaning buildings. Journal of Cultural Heritage, 12(2), 117-127. https://doi.org/10.1016/j.culher.2011.01.002

Pieraccini, M., Dei, D., Betti, M., Bartoli, G., Tucci, G., \& Guardini, N. (2014). Dynamic identification of historic masonry towers through an expeditious and no-contact approach: Application to the "Torre del Mangia" in Siena (Italy). Journal of Cultural Heritage, 15(3), 275-282. https://doi.org/10.1016/j.culher.2013.07.006

Roca, P. (2009). Study of Gothic churches: inspection, monitoring and structural analysis. In Tecnología de la Rehabilitación y Gestión del Patrimonio Construido (REHABEND 2009) (pp. 1-19). Bilbao, Spain.

Rodríguez-Mayorga, E., Yanes-Bustamante, E., \& Sáez-Pérez, A. (2015). Analysis and Diagnosis of the Church of Santiago in Jerez de la Frontera (Spain). Informes de La Construcción, 67(540), e127. https://doi.org/10.3989/ic.15.030

Schueremans, L. (2008). Appraisal of 3 different non-destructive techniques for masonry heritage structures and their practical applicability. In Tecnología de la Rehabilitación y Gestión del Patrimonio Construido (REHABEND 2008) (pp. 25-32). Valencia, Spain.

Teza, G., \& Pesci, A. (2013). Geometric characterization of a cylinder-shaped structure from laser scanner data: Development of an analysis tool and its use on a leaning bell tower. Journal of Cultural Heritage, 14(5), 411-423. https://doi.org/10.1016/j.culher.2012.10.015

US Army Corps of Engineers. (2002). Engineering and Design. Structural Deformation Surveying. Manual n EM-1110-1-1005. US Army Corps of Engineers.

US Army Corps of Engineers. (2007). Engineering and Design. Control and Topographic Surveying. Manual n EM-1110-1-1005. US Army Corps of Engineers.

Valle-Melón, J. M., Rodríguez-Miranda, Á., \& Pérez-Vidiella, P. (2011). Detección del movimiento cíclico estacional en edificios históricos por métodos topográficos. Materiales de Construcción, 61(301), 131-142. https://doi.org/10.3989/mc.2011.54409

Valle Melón, J. M., Rodríguez Miranda, Á., \& Pérez Vidiella, P. (2008). Evaluation of the conventional surveying equipment applied to deformation analysis of heritage buildings. A case study: the bell tower of Santa María la Blanca church in Agoncillo (La Rioja, Spain). In Measuring the changes, 13th FIG International Symposium on Deformation Measurements and Analysis and 4th IAG Symposium on Geodesy for Geotechnical and Structural Engineering. Lisbon (Portugal).

Welsch, W. M., \& Heunecke, O. (2001). Models and terminology for the analysis of geodetic monitoring observations. International Federation of Surveyors. 